\title{
Radiofrequency catheter ablation of ventricular tachycardia in arrhythmogenic right ventricular dysplasia/ cardiomyopathy using non-contact electroanatomical mapping: single-center experience with follow-up up to median of 30 months
}

\author{
Mohan Nair • Amitabh Yaduvanshi • Vikas Kataria • \\ Manoj Kumar \\ Received: 8 October 2010 /Accepted: 10 February 2011 /Published online: 25 March 2011 \\ (C) The Author(s) 2011. This article is published with open access at Springerlink.com
}

\begin{abstract}
Objective of study To evaluate the efficacy of radiofrequency ablation (RFA) of ventricular tachycardia (VT) using noncontact electro-anatomic mapping in patients with arrhythmogenic right ventricular dysplasia/cardiomyopathy (ARVD/C). Methods Fifteen consecutive patients ( $44 \pm 15$ years) with ARVD/C and symptomatic VTs were studied. Eight patients had syncopal VTs. Two patients had recurrent VT while on AICD; in three patients, RFA was done prior to AICD implantation, and ten patients refused AICD. After obtaining activation maps, first, the clinical VT was targeted, and then, other VTs were sought.

Results Twenty-five inducible VTs were mapped, and 22 of them were successfully ablated. In 13 out of 15 patients, all the clinical and inducible VTs were ablated. In two patients, nonclinical inducible VTs could not be ablated. At $25 \pm 16$ months (2-52 months), all patients remained asymptomatic. Antiarrhythmic medications were discontinued after 6 months. Two patients had recurrence of non-clinical VT on follow-up. There were no episodes of asymptomatic VT recorded in five patients with AICD.
\end{abstract}

M. Nair $\cdot$ A. Yaduvanshi $\cdot$ V. Kataria $\cdot$ M. Kumar

Department of Cardiology, Max Healthcare,

New Delhi, India

\section{Nair $(\bowtie)$}

Department of Electrophysiology and Arrhythmia Services,

Max Super Speciality Hospital,

108A, I P Extension, Patparganj,

New Delhi, India 110092

e-mail: mohancardio@gmail.com
Conclusion A majority of induced VT in patients with ARVD/C can be successfully mapped and ablated using the non-contact Ensite Array Mapping system with good longterm VT-free outcome. Ablation can be a useful adjunct to AICD implantation in such patients.

Keywords ARVD/C - Radiofrequency ablation . Electroanatomical mapping · Ventricular tachycardia

\begin{tabular}{|c|c|}
\hline \multicolumn{2}{|c|}{ Abbreviations } \\
\hline $\mathrm{ARVD} / \mathrm{C}$ & $\begin{array}{l}\text { Arrhythmogenic right ventricular dysplasia/ } \\
\text { cardiomyopathy }\end{array}$ \\
\hline PVCs & Premature ventricular contractions \\
\hline AICD & $\begin{array}{l}\text { Automated implantable cardioverter- } \\
\text { defibrillator }\end{array}$ \\
\hline RFA & Radiofrequency catheter ablation \\
\hline $3 \mathrm{D}$ & Three-dimensional \\
\hline VT & Ventricular tachycardia \\
\hline ECG & Electrocardiogram \\
\hline RV & Right ventricular \\
\hline RVOT & Right ventricular outflow tract \\
\hline
\end{tabular}

Arrhythmogenic right ventricular dysplasia/cardiomyopathy (ARVD/C) is an inherited cardiomyopathy characterized by fibro-fatty replacement primarily of right ventricular muscle. This results in a heterogeneous structure of the right ventricular myocardium which causes ventricular arrhythmias, including PVCs, and non-sustained or sustained ventricular tachycardia and sudden death due to ventric- 
ular fibrillation. Structural or functional alterations of the right and left ventricles may lead to congestive heart failure [1-3]. ARVD/C is uncommon, but may account for up to $20 \%$ of cases of sudden death among young individuals [4-7].

Since patients with ARVD/C are at significantly high risk of sudden cardiac death, most people with this condition are advised automated implantable cardioverter-defibrillator (AICD) implantation. However, high rates of appropriate AICD firing among patients with ARVD/C have been reported in multiple studies [8-12]. Consequently, adjunctive treatment with antiarrhythmic drug therapy and/or radiofrequency catheter ablation (RFA) is commonly recommended.

The acute- and long-term efficacy of radiofrequency catheter ablation in patients with $\mathrm{ARVD} / \mathrm{C}$ still remains unclear. Most previous studies have used either conventional mapping alone or a combination of conventional and $3 \mathrm{D}$ electroanatomical mapping, thus clouding the results [12-17].

We report the acute- and intermediate-term results of RFA using the non-contact Ensite Array Mapping system (St. Jude Medical, St. Paul, MN) in Indian patients with ARVD/C. All patients met the criteria for ARVD/C diagnosis as defined by the International Task Force [18].

\section{Methods}

All patients who underwent RFA guided by non-contact electroanatomical mapping and satisfied the International
Task Force criteria for ARVD/C were included in a prospective analysis. Each patient had previously experienced two or more episodes of sustained VT. All patients gave written informed consent for RFA.

Clinical VT(s) were defined by several techniques, including a comparison of 12-lead electrocardiographic morphologies of induced and spontaneous VT, and when a 12-lead electrocardiogram of the clinical VT was not available, by comparison of induced and spontaneous VT cycle lengths. Electroanatomical mapping was used to facilitate ablation during all procedures in 15 patients $[19,20]$.

The EnSite Array Mapping system is a computerized system that creates three-dimensional electroanatomical maps without the need for point-by-point contact electrograms and was used in all the patients. In this system, noncontact balloon catheter creates virtual unipolar electrograms using a mathematical inverse solution to estimate the electrical potentials which allows for non-contact mapping of conduction through a cardiac chamber in a single cycle of the tachycardia. This system is particularly useful for mapping and ablation of VT in cardiomyopathies as activation maps for non-sustained as well as hemodynamically unstable VTs can be obtained easily. The endocardial breakthrough site of the VT was defined at the point of onset of a sharp QS deflection on the unipolar virtual electrogram. The endocardial breakthrough sites were further confirmed using entrainment and/or pace mapping. Then, linear or circumferential RF lesions were given to encompass a wide area around this site (Fig. 1). Low-amplitude, diastolic potentials were also invariably seen at the successful ablation sites.

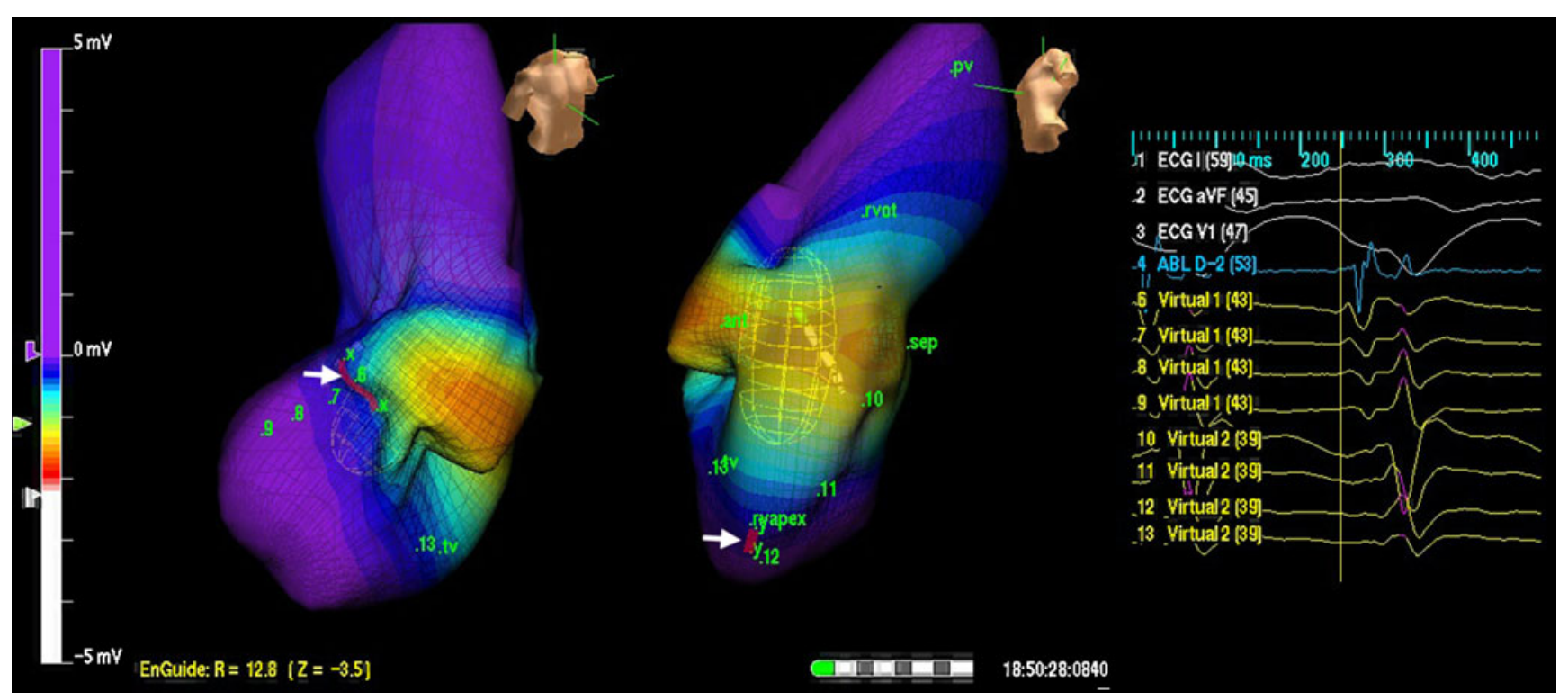

Fig. 1 Ensite Map of VT in a patient with VT of multiple morphologies. All the VTs were, however, shown to turn around a single area in the RV (red line-white arrow). Ablation along this line rendered all the VTs non-inducible; 52 months follow-up has shown one episode of asymptomatic slow VT. $V T$ ventricular tachycardia; $R V$ right ventricular 
This, however, was not specific, as fragmented ventricular electrograms and diastolic potentials could also be recorded at sites in the RV not responsible for VT.

The Ensite Array catheter was positioned either at the RV apex and/or the RVOT depending on the expected site of origin of VT from the scalar ECG morphology. VT was induced using programmed stimulation. Induction protocol consisted of programmed stimulation at two cycle lengths at two RV sites and up to three extrastimuli. Drugs such as isoprenaline were not used in any patient for induction. The first goal was to target the clinical VT and then look for any other VT.

Standard radiofrequency energy $\left(60 \mathrm{~W}\right.$ power, $60^{\circ} \mathrm{C}$ temperatures for $60 \mathrm{~s}$ ) delivered through 4-mm tipped deflectable ablation catheters were used for each of the ablation procedure. Ablation of a particular morphology of VT was considered successful if the VT terminated during radiofrequency application and/or it could not be induced on repeated stimulation. Procedural success was defined as total when all of the inducible VTs could be successfully mapped and ablated, partial when not all of the inducible VTs were successfully ablated, but the clinical VT was successfully ablated, and failure if none of the inducible VTs could be ablated successfully.

\subsection{Follow-up}

Patients were followed up routinely in out-patient clinics; the patient underwent monthly 24-h Holter monitoring for 6 months and then three monthly Holter monitoring. Patients were also advised to strictly report any symptom of palpitation or syncope/presyncope. They were also told to have a12-lead electrogram taken in case they developed palpitation. AICD interrogation reports from patients with AICD were analyzed whenever available. Appropriateness of AICD intervention was defined using the standard criteria. VT recurrence was defined as an appropriate AICD intervention or the occurrence of sustained VT of at least 30 -s duration or any hemodynamically significant VT subsequent to the ablation procedure as documented by a 12-lead electrocardiogram, an event monitor, or a 24-h Holter monitor. The time to VT recurrence after each ablation procedure was noted. Long-term success was defined as the absence of recurrence of VT over follow-up.

\section{Results}

Study population A total of $15 \mathrm{ARVD} / \mathrm{C}$ patients with at least two episodes of clinical VT underwent catheter ablation for VT. The mean age at the time of the procedure was $44 \pm 15$ years. Twelve $(80 \%)$ of the 15 patients were male. All patients were symptomatic, and eight patients had syncopal VT. All patients were advised AICD implantation in view of the progressive nature of their disease and the standard recommendations in such patients. Two patients were taken up for ablation of recurrent VT occurring while on an AICD; three underwent AICD implantation following the RF ablation, and the other ten patients declined AICD due to financial constrains. In one patient, the ablation was done for recurrence following a previous ablation procedure done using conventional mapping technique.

Electrophysiology study, mapping, and ablation Table 1 shows the electrophysiological details of each of the 15 patients. Four patients had clinical VT with multiple morphologies. All patients had VT induced during baseline electrophysiological testing with multiple VT morphology induced in six patients. In four patients, the induced nonsustained VT with a fall in blood pressure but the short duration was enough to get relevant information on the noncontact map for guiding ablation. In one patient, VT induced after ablation of the clinical VT caused hemodynamic collapse requiring DC cardioversion; however, the short run of VT prior to cardioversion was sufficient to map the tachycardia (Fig. 2). Mapping of VT was performed using 3-dimensional electroanatomical mapping with the Ensite Array catheter positioned in RV apex in eight patients and RV outflow tract in seven patients. Thirteen patients had all their VTs coming from a single region (RV apex or the outflow tract), while one had VTs originating from the apical as well as the outflow tract region (Fig. 2). In one patient, the 3D mapping showed breakthrough in the outflow tract. Intracardiac electrograms, however, showed a sharp potential, which followed the RV electrogram during sinus rhythm, but preceded it during VT (Fig. 3). This potential was mapped to originate in the pulmonary artery. While ablation at the RV outflow tract failed to eliminate the arrhythmia, ablation within the pulmonary artery successfully terminated the arrhythmia and rendered it non-inducible. In all 26 VTs, all clinical VTs were mapped, and 23 VTs were ablated with an acute procedural success rate of $88 \%$.

All the inducible VTs were ablated successfully in 13 patients; in two patients, non-clinical inducible VTs could not be ablated. The clinical VT was successfully ablated and could not be re-induced with programmed electrical stimulation in all the patients with an acute clinical success rate of $100 \%$. There was no peri-procedural complication, and all patients were discharged from the hospital following $48 \mathrm{~h}$ of the procedure.

Long-term follow-up The follow-up duration between the first ablation procedure and the last out-patient clinic visit was $25 \pm 16$ months (range, 2 to 52 months). All patients remained asymptomatic. Routine monthly Holter recordings of all patients for 6 months were analyzed, and there were no episodes of sustained VT, and the numbers of ventricular 
Table 1 Electrophysiological details of each of the 15 patients

\begin{tabular}{|c|c|c|c|c|c|c|c|c|c|}
\hline $\begin{array}{l}\text { Subject } \\
\text { number }\end{array}$ & $\begin{array}{l}\text { Age, } \\
\text { years }\end{array}$ & $\begin{array}{l}\text { Syncopal } \\
\text { VT }\end{array}$ & $\begin{array}{l}\text { Number of } \\
\text { clinical VTs }\end{array}$ & $\begin{array}{l}\text { ICD before } \\
\text { RFA }\end{array}$ & $\begin{array}{l}\text { Number of } \\
\text { VT induced }\end{array}$ & $\begin{array}{l}\text { Number of } \\
\text { VT ablated }\end{array}$ & $\begin{array}{l}\text { ICD after } \\
\text { ablation }\end{array}$ & VT recurrence & $\begin{array}{l}\text { Follow-up, } \\
\text { months }\end{array}$ \\
\hline 1 & 52 & Yes & 3 & No & 4 & 3 & No & 1-Slow VT & 53 \\
\hline 2 & 8 & Yes & 1 & No & 1 & 1 & No & No recurrence & 45 \\
\hline 3 & 48 & Yes & 1 & Yes & 1 & 1 & NA & No recurrence & 44 \\
\hline 4 & 44 & Yes & 2 & No & 2 & 2 & No & No recurrence & 38 \\
\hline 5 & 58 & Yes & 1 & No & 1 & 1 & Yes & 1 & 37 \\
\hline 6 & 32 & No & 1 & No & 1 & 1 & No & No recurrence & 33 \\
\hline 7 & 56 & No & 3 & No & 3 & 3 & Yes & No recurrence & 34 \\
\hline 8 & 49 & Yes & 1 & No & 3 & 1 & Yes & No recurrence & 28 \\
\hline 9 & 60 & Yes & 1 & No & 1 & 1 & No & No recurrence & 24 \\
\hline 10 & 48 & No & 1 & Yes & 1 & 1 & NA & No recurrence & 16 \\
\hline 11 & 33 & Yes & 3 & No & 3 & 3 & No & No recurrence & 13 \\
\hline 12 & 36 & No & 1 & No & 2 & 2 & No & No recurrence & 11 \\
\hline 13 & 20 & No & 1 & No & 1 & 1 & No & No recurrence & 7 \\
\hline 14 & 34 & No & 1 & No & 1 & 1 & No & No recurrence & 6 \\
\hline 15 & 39 & No & 1 & No & 1 & 1 & No & No recurrence & 3 \\
\hline
\end{tabular}

$V T$ ventricular tachycardia, $I C D$ implantable cardioverter defibrillator, $N A$ not applicable

ectopics significantly decreased. Antiarrhythmic medications were discontinued if there was no recurrence of VT for at least 6 months (Table 2). Antiarrhythmic medication could be withdrawn in all patients after $6-8$ months of ablation. One patient had a recurrence of slow VT at the rate of $146 \mathrm{bpm}$, after 17 weeks of ablation which was clinically silent and was picked up on Holter. One patient who underwent AICD implantation after ablation had an appropriate therapy for a

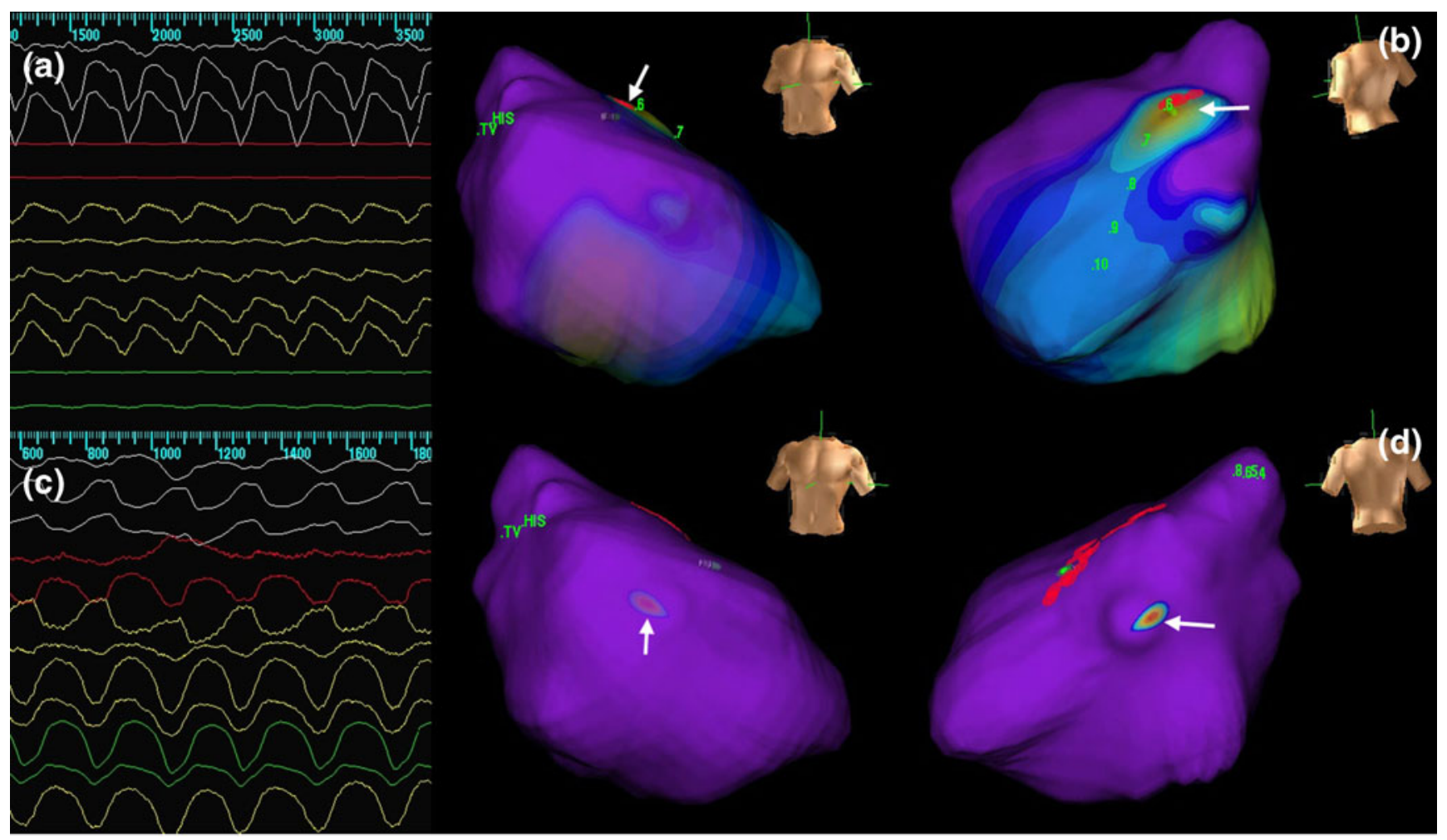

Fig. 2 Electrocardiograms and endocardial activation maps in a patient having VTs with two different morphologies and cycle lengths. One VT was ablated successfully in the RVOT region, whereas the other one was seen to originate more apically in the RV. $V T$ ventricular tachycardia; $R V$ right ventricular 


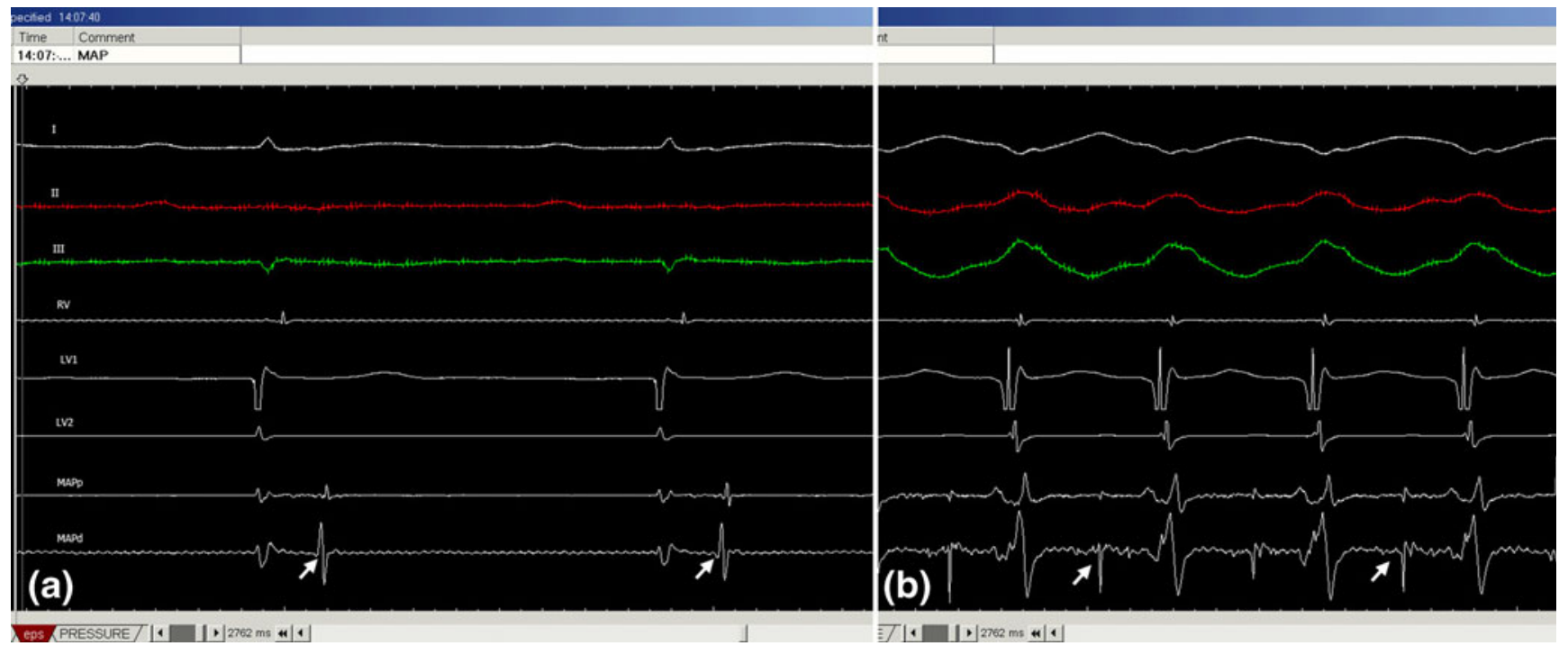

Fig. 3 Ventricular tachycardia originating in the pulmonary artery. Note sharp potential (arrow) following RV potential during sinus rhythm (a) and preceding the RV potential during VT (b)

single episode of recurrence of VT, 21 months after the procedure. In the five patients with ICDs, there were no asymptomatic episodes detected nor were there any detected on Holter monitors in the patients without ICDs.

\section{Discussion}

Our results show that catheter ablation of VT in patients with $\mathrm{ARVD} / \mathrm{C}$ is associated with high acute procedural success and good intermediate-term outcomes with the use of non-contact electroanatomical mapping systems to guide the ablation.

In 1998, Ellison et al. [15] reported the acute- and longterm outcome of catheter ablation in five ARVD/C patients. During a mean follow-up of 17 months, none of these patients had recurrent VT; however, three patients were continuing on antiarrhythmic drugs. In 2003, Reithmann et al. [21] used electroanatomical mapping system to ablate VT in five patients with ARVD/C. During a mean follow-up of

Table 2 Antiarrhythmic medications

\begin{tabular}{|c|c|c|c|c|c|c|c|}
\hline $\begin{array}{l}\text { Subject } \\
\text { number }\end{array}$ & $\begin{array}{l}\text { Age, } \\
\text { years }\end{array}$ & $\begin{array}{l}\text { Pre-ablation } \\
\text { VPC frequency } \\
\text { VPC/ } 24 \mathrm{~h}\end{array}$ & $\begin{array}{l}\text { Post-ablation } \\
\text { VPC frequency } \\
\text { VPC/ } 24 \mathrm{~h}\end{array}$ & $\begin{array}{l}\text { Antiarrhythmic } \\
\text { drugs used prior } \\
\text { to ablation }\end{array}$ & $\begin{array}{l}\text { Antiarrhythmic } \\
\text { drugs used } \\
\text { after ablation }\end{array}$ & $\begin{array}{l}\text { Duration of } \\
\text { antiarrhythmic } \\
\text { drugs after ablation } \\
\text { (months) }\end{array}$ & $\begin{array}{l}\text { Follow-up } \\
\text { (months) }\end{array}$ \\
\hline 1 & 52 & 14,524 & 4,658 & Amiodarone and metoprolol & Amiodarone & 7 & 53 \\
\hline 2 & 8 & 12,457 & 9,854 & Amiodarone & Amiodarone & 7 & 45 \\
\hline 3 & 48 & 9,586 & 3,567 & Amiodarone and metoprolol & Amiodarone & 8 & 44 \\
\hline 4 & 44 & 25,463 & 11,287 & Amiodarone & Amiodarone & 6 & 38 \\
\hline 5 & 58 & 4,502 & 2,146 & Amiodarone and metoprolol & Amiodarone & 7 & 37 \\
\hline 6 & 32 & 3,589 & 118 & Amiodarone and metoprolol & Amiodarone & 7 & 33 \\
\hline 7 & 56 & 12,456 & 5,478 & Amiodarone and metoprolol & Amiodarone & 7 & 34 \\
\hline 8 & 49 & 9,845 & 2,458 & Amiodarone & Amiodarone & 6 & 28 \\
\hline 9 & 60 & 2,589 & 452 & Amiodarone & Amiodarone & 6 & 24 \\
\hline 10 & 48 & 11,244 & 245 & Amiodarone and metoprolol & Amiodarone & 6 & 16 \\
\hline 11 & 33 & 8,574 & 1,142 & Amiodarone & Amiodarone & 6 & 13 \\
\hline 12 & 36 & 1,554 & 1,283 & Amiodarone & Amiodarone & 7 & 11 \\
\hline 13 & 20 & 15,789 & 8,457 & Amiodarone and metoprolol & Amiodarone & 6 & 7 \\
\hline 14 & 34 & 1,145 & 1,352 & Amiodarone and metoprolol & Amiodarone & 6 & 6 \\
\hline 15 & 39 & 8,569 & 3,478 & Amiodarone & Amiodarone & 3 & 3 \\
\hline
\end{tabular}

$V P C$ ventricular premature complexes 
7 months, $60 \%$ of patients were free of recurrent VT with amiodarone continued in three patients.

Use of electroanatomical mapping has also been reported by Marchlinski et al. [22] and Verma et al. [23]. In Marchlinski's study acute success, defined as the absence of all inducible VTs, was achieved in 14 (74\%) of 19 patients. During a mean follow-up of $27 \pm 22$ months, 17 $(89 \%)$ of 19 patients were free of recurrent VT. However, in this series, repeat ablation procedures were required in $68 \%$ of patients, and the use of antiarrhythmic drugs were not reported. Thus, the success rates of a single procedure were low. In Verma's study, catheter ablation in 22 patients with $\mathrm{ARVD} / \mathrm{C}$, each of whom had hemodynamically unstable VT, was reported. Acute success with no inducible VT at the end of the procedure was achieved in $18(82 \%)$ patients, with VT recurrence rates despite continued antiarrhythmic therapy of $23 \%, 27 \%$, and $47 \%$ at 1,2 , and 3 years, respectively.

Catheter ablation results The results of this study are in keeping with the high success rate reported by Ellison et al. [15] and Marchlinski et al. [22]. However, it differs from studies by Dalal et al. [17], Reithmann et al. [21], and Verma et al. [23] due to the considerable recurrence rate reported in these reports. Reithmann et al. [21] reported a $40 \%$ recurrence rate during a mean follow-up of 7 months, and Verma et al. [23] reported a recurrence rate of $47 \%$ at 3 years of follow-up.

The dichotomy in the procedural success rates have been tried to be explained on the basis of the different modes of mapping used in the previous studies. Substrate base ablation using 3D electroanatomical mapping has been used with good success rates in ablation of VT in complex substrates such as post-infarction [24] and cardiomyopathies; however, in the study by Dalal et al. [17], only $21 \%$ patients had ablation done using 3D electroanatomical mapping. Furthermore, all the studies alluded to above have used pointby-point-based mapping and ablation systems. Moreover, most of the earlier large studies have pooled data from several centers, with recruitment rates as low as two patients from a single center, resulting in confounding, non-uniform results $[17,22,23]$. Our study used the noncontact mapping system which has a potential advantage in this setting, as it allows mapping of non-sustained as well as hemodynamically unstable VTs. This is agreement with the study by Yao et al. [25] who used non-contact mapping in similar subset of patients.

Epicardial mapping and ablation has also been used successfully in patients with ventricular tachycardias [26-28]. Recently, Garcia et al. [29] have published their experience with epicardial mapping and combined endocardial and epicardial ablation in patients with $\mathrm{ARVD} / \mathrm{C}$ who had an earlier failed endocardial procedure with $10 / 13$ patients (77\%) remaining free from VT at 18 months follow-up. This has added a new approach in our armamentarium to ablate ventricular tachycardia in ARVD/C. The relative absence of epicardial VTs in our study was a little surprising and could not be easily explained. This, however, does not dilute the feasibility and importance of catheter ablation of ventricular tachycardia in ARVD/C.

Limitations of the study Our study was limited by the fact that only five patients had AICD implanted and, hence, true recurrence of asymptomatic VT could be assessed only in these patients; however, the other patients had regular clinical and Holter-based follow-up and their recurrence rates assessed.

Another limitation is the relatively short duration of follow-up in many patients, and four patients have not yet completed 6 months of drug-free follow-up.

Our study suggests that using non-contact mapping, which has an advantage of mapping even non-sustained or hemodynamically unstable VT, to guide the ablation strategy improves the acute- and intermediate-term success rates of ablation in these patients as compared with earlier reported case series that have not used this mapping technology.

In conclusion, ablation guided by non-contact mapping may prove to be an attractive complement to AICD in preventing VT and sudden cardiac death in patients with $\mathrm{ARVD} / \mathrm{C}$.

Conflict of interest No relevant disclosures

Open Access This article is distributed under the terms of the Creative Commons Attribution Noncommercial License which permits any noncommercial use, distribution, and reproduction in any medium, provided the original author(s) and source are credited.

\section{References}

1. Marcus, F., \& Fontaine, G. (1995). Arrhythmogenic right ventricular dysplasia/cardiomyopathy, a review. Pacing and Clinical Electrophysiology, 18, 1298-1314.

2. Kies, P., Bootsma, M., Bax, J., et al. (2006). Arrhythmogenic right ventricular dysplasia/cardiomyopathy: Screening, diagnosis, and treatment. Heart Rhythm, 3, 225-234.

3. Sen-Chowdhry, S., Lowe, M. D., Sporton, S. C., et al. (2004). Arrhythmogenic right ventricular cardiomyopathy: Clinical presentation, diagnosis, and management. American Journal of Medicine, 117, 685-695.

4. Thiene, G., Nava, A., Corrado, D., et al. (1988). Right ventricular cardiomyopathy and sudden death in young people. The New England Journal of Medicine, 318, 129-133.

5. Maron, B. J. (1998). Cardiovascular risks to young persons on the athletic field. Annals of Internal Medicine, 129, 379-386.

6. Marcus, F. I. (1998). Right ventricular dysplasia: Evaluation and management in relation to sports activities. In N. A. M. Estes, D. 
N. Salem, \& P. J. Wang (Eds.), Sudden Cardiac Death in the Athlete (pp. 277-284). Armonk, NY: Futura Publishing Co., Inc.

7. Corrado, D., Basso, C., Rizzoli, G., et al. (2003). Does sports activity enhance the risk of sudden death in adolescents and young adults? Journal of the American College of Cardiology, 42, 1959-1963.

8. Dalal, D., Nasir, K., Bomma, C., et al. (2005). Arrhythmogenic right ventricular dysplasia: A United States experience. Circulation, 112, 3823-3832.

9. Corrado, D., Leoni, L., Link, M. S., et al. (2003). Implantable cardioverter defibrillator therapy for prevention of sudden death in patients with arrhythmogenic right ventricular cardiomyopathy/ dysplasia. Circulation, 108, 3084-3091.

10. Wichter, T., Paul, M., Wollmann, C., et al. (2004). Implantable cardioverter defibrillator therapy in arrhythmogenic right ventricular cardiomyopathy: Single-center experience of long-term follow-up and complications in 60 patients. Circulation, 109, $1503-1508$.

11. Roguin, A., Bomma, C. S., Nasir, K., et al. (2004). Implantable cardioverter defibrillators in patients with arrhythmogenic right ventricular dysplasia/ cardiomyopathy. Journal of the American College of Cardiology, 43, 1843-1852.

12. Piccini, J. P., Dalal, D., Roguin, A., et al. (2005). Predictors of appropriate implantable defibrillator therapies in patients with arrhythmogenic right ventricular dysplasia. Heart Rhythm, 2, 1188-1194.

13. Fontaine, G., Frank, R., Rougier, I., et al. (1989). Electrode catheter ablation of resistant ventricular tachycardia in arrhythmogenic right ventricular dysplasia: Experience of 13 patients with a mean followup of 45 months. European Heart Journal, 10, 74-81.

14. Fontaine, G., Frank, R., Rougier, I., et al. (1990). Electrode catheter ablation of resistant ventricular tachycardia in arrhythmogenic right ventricular dysplasia: Experience of 15 patients with a mean follow-up of 45 months. Heart and Vessels, 5, 172-187.

15. Ellison, K. E., Friedman, P. L., Ganz, L. I., et al. (1998). Entrainment mapping and radiofrequency catheter ablation of ventricular tachycardia in right ventricular dysplasia. Journal of the American College of Cardiology, 32, 724-728.

16. Fontaine, G., Tonet, J., Gallais, Y., et al. (2000). Ventricular tachycardia catheter ablation in arrhythmogenic right ventricular dysplasia: A 16-year experience. Current Cardiology Reports, 2, 498-506.

17. Dalal, D., Jain, R., Tandri, H., et al. (2007). Long-Term Efficacy of Catheter Ablation of Ventricular Tachycardia in Patients With Arrhythmogenic Right Ventricular Dysplasia/Cardiomyopathy. Journal of the American College of Cardiology, 50, 432-440.

18. McKenna, W. J., Thiene, G., Nava, A., et al. (1994). Diagnosis of arrhythmogenic right ventricular dysplasia/cardiomyopathy. Task
Force of the Working Group Myocardial and Pericardial Disease of the European Society of Cardiology and of the Scientific Council on Cardiomyopathies of the International Society and Federation of Cardiology. British Heart Journal, 71, 215-218.

19. Hsia, H. H., Callans, D. J., \& Marchlinski, F. E. (2003). Characterization of endocardial electrophysiological substrate in patients with nonischemic cardiomyopathy and monomorphic ventricular tachycardia. Circulation, 108, 704-710.

20. Marchlinski, F. E., Callans, D. J., Gottlieb, C. D., et al. (2000). Linear ablation lesions for control of unmappable ventricular tachycardia in patients with ischemic and nonischemic cardiomyopathy. Circulation, 101, 1288-1296.

21. Reithmann, C., Hahnefeld, A., Remp, T., et al. (2003). Electroanatomical mapping of endocardial right ventricular activation as a guide for catheter ablation in patients with arrhythmogenic right ventricular dysplasia. Pacing and Clinical Electrophysiology, 26, $1308-1316$

22. Marchlinski, F. E., Zado, E., Dixit, S., et al. (2004). Electroanatomical substrate and outcome of catheter ablative therapy for ventricular tachycardia in setting of right ventricular cardiomyopathy. Circulation, 110, 2293-2298.

23. Verma, A., Kilicaslan, F., Schweikert, R. A., et al. (2005). Short- and long-term success of substrate-based mapping and ablation of ventricular tachycardia in arrhythmogenic right ventricular dysplasia. Circulation, 111, 3209-3216.

24. Reddy, V., Reynolds, M., Neuzil, P., et al. (2007). Prophylactic catheter ablation for the prevention of defibrillator therapy. The New England Journal of Medicine, 357(26), 2657-2665.

25. Yao, Y., Zhang, S., He, D. S., et al. (2007). Radiofrequency ablation of the ventricular tachycardia with arrhythmogenic right ventricular cardiomyopathy using non-contact mapping. Pacing and Clinical Electrophysiology, 30(4), 526-533.

26. Tedrow, U., \& Stevenson, W. G. (2009). Strategies for epicardial mapping and ablation of ventricular tachycardia. Journal of Cardiovascular Electrophysiology, 20, 710-713.

27. Grimard, C., Lacotte, J., Hidden-Lucet, F., et al. (2010). Percutaneous epicardial radiofrequency ablation of ventricular arrhythmias after failure of endocardial approach: A nine-year experience. $J$ of Cardiovascular Electrophysiol, 21, 56-61.

28. Sacher, F., Roberts-Thomson, K., Maury, P., et al. (2010). Epicardial ventricular tachycardia ablation: A multi-center safety study. Journal of the American College of Cardiology, 55, 23662372.

29. Garcia, F., Bazan, V., Zado, E., et al. (2009). Epicardial Substrate and Outcome with Epicardial Ablation of Ventricular Tachycardia in Arrhythmogenic Right Ventricular Cardiomyopathy/Dysplasia. Circulation, 120, 366-375. 